\title{
A single amino acid change within the R2 domain of the VvMYB5b transcription factor modulates affinity for protein partners and target promoters selectivity
}

Imène Hichri ${ }^{1,2,3}$, Laurent Deluc ${ }^{4}$, François Barrieu ${ }^{1,2,3}$, Jochen Bogs $5^{5,6}$, Ali Mahjoub ${ }^{1,2,3}$, Farid Regad ${ }^{7}$, Bernard Gallois ${ }^{8}$, Thierry Granier ${ }^{8}$, Claudine Trossat-Magnin ${ }^{1,2,3}$, Eric Gomès ${ }^{1,2,3}$ and Virginie Lauvergeat ${ }^{1,2,3^{*}}$

\begin{abstract}
Background: Flavonoid pathway is spatially and temporally controlled during plant development and the transcriptional regulation of the structural genes is mostly orchestrated by a ternary protein complex that involves three classes of transcription factors (R2-R3-MYB, bHLH and WDR). In grapevine (Vitis vinifera L.), several MYB transcription factors have been identified but the interactions with their putative bHLH partners to regulate specific branches of the flavonoid pathway are still poorly understood.

Results: In this work, we describe the effects of a single amino acid substitution (R69L) located in the R2 domain of VVMYB5b and predicted to affect the formation of a salt bridge within the protein. The activity of the mutated protein (name VVMYB5b', the native protein being referred as $V_{V M Y B 5 b^{R}}$ ) was assessed in different in vivo systems: yeast, grape cell suspensions, and tobacco. In the first two systems, $V_{V M Y B 5} b^{L}$ exhibited a modified trans-activation capability. Moreover, using yeast two-hybrid assay, we demonstrated that modification of VVMYB5b transcriptional properties impaired its ability to correctly interact with VVMYC1, a grape bHLH protein. These results were further substantiated by overexpression of $V V M Y B 5 b^{R}$ and $V V M Y B 5 b^{L}$ genes in tobacco. Flowers from $355 .: 1 V M Y Y B 5 b^{L}$ transgenic plants showed a distinct phenotype in comparison with $355 .: V V M Y B 5 b^{R}$ and the control plants. Finally, significant differences in transcript abundance of flavonoid metabolism genes were observed along with variations in pigments accumulation.

Conclusions: Taken together, our findings indicate that $\mathrm{VVMYB}^{\mathrm{L}} \mathrm{b}^{\mathrm{L}}$ is still able to bind DNA but the structural consequences linked to the mutation affect the capacity of the protein to activate the transcription of some flavonoid genes by modifying the interaction with its co-partner(s). In addition, this study underlines the importance of an internal salt bridge for protein conformation and thus for the establishment of protein-protein interactions between MYB and bHLH transcription factors. Mechanisms underlying these interactions are discussed and a model is proposed to explain the transcriptional activity of $\mathrm{VVMYB5}^{\mathrm{L}}$ observed in the tobacco model.
\end{abstract}

\section{Background}

MYB proteins represent a diverse and widely distributed class of eukaryotic transcription factors. In plants, $M Y B$ genes constitute a very large family encompassing 198 members in Arabidopsis thaliana for instance. Such large families are also observed in rice (Oryza sativa L.

\footnotetext{
* Correspondence: virginie.lauvergeat@bordeaux.inra.fr

'Univ. de Bordeaux, Institut des Sciences de la Vigne et du Vin (ISW), UMR 1287 Ecophysiologie et Génomique Fonctionnelle de la Vigne (EGFV), 210

Chemin de Leysotte, 33882 Villenave d'Ornon, France

Full list of author information is available at the end of the article
}

ssp. indica) and grape (Vitis vinifera L.), with no less than 85 and 108 members, respectively [1-3]. Plant MYB proteins are involved in the regulation of numerous physiological processes [4] and are for example notoriously known to regulate the phenylpropanoid pathway, allowing the biosynthesis of flavonoid, stilbenes and lignin compounds [4-7].

It is now well established that MYB proteins involved in the regulation of the anthocyanin and proanthocyanidin (PA) pathways act synergistically with bHLH partners (basic Helix Loop Helix) and WD-repeat proteins

\section{() Biomed Central}


(WDR or WD40) to enhance the expression of structural genes (reviewed in [8-10]). Such tripartite MYBbHLH-WDR (MBW) complexes were found to regulate anthocyanin biosynthesis in petunia flowers [11-13] and PA accumulation in Arabidopsis seed coat [14]. In grapevine, several branches of flavonoid biosynthesis are under the transcriptional control of different MYBs proteins [15-21]. Among them, two MYB transcription factors, VvMYB5a and VvMYB5b, contribute to the transcriptional regulation of the common parts of the pathway [20,21]. $V v M Y B 5 b$ is expressed in grape berry during PA synthesis in seeds and anthocyanin accumulation in skin. In tobacco, $V v M Y B 5 b$ ectopic expression resulted in accumulation of anthocyanins and PAs in flowers (stamens and petals), with no visible changes in vegetative organs [21]. As previously described in Arabidopsis and Petunia, MYB transcription factors require a bHLH partner for the trans-activation of flavonoid structural genes $[17,21]$. Recently, two bHLH transcription factors (VvMYC1 and VvMYCA1) and two WDR proteins (WDR1 and WDR2) have been identified in grapevine [22,23]. VvMYB5b interacts in yeast and in planta with VvMYC1 [22]. Thus, in grape berry, the interplay between each component of the MBW complex was proposed to control the spatiotemporal distribution of each class of flavonoid compounds. In this spatiotemporal control, three components must play a critical role: (i) the presence of the proteins at a given time in a given tissue, (ii) the DNA binding affinity of each of these proteins for their target genes, and (iii) the specific combination between partners that will result in the activation of a specific structural gene expression. Although the protein-protein interaction between MYB and bHLH proteins has been already investigated in vitro [24-26], the mechanisms underlying the formation of the whole MBW transcriptional complex have not been identified yet. In this complex, MYB proteins play a critical role in the determination of cis-elements and thus contribute to the selection of target genes. However, the affinity between MYB proteins and cis-elements may partly depend on the nature of the interacting bHLH partner, taking in account the fact that the interaction can modify the structural conformation of the MYB DNA-Binding domain [9,27-29].

MYB proteins are characterized by the presence of an extremely well conserved N-terminal domain that contains up to three imperfect $\mathrm{R}$ repeats (R1, R2 and R3) of about 53 amino acid residues each. These repeats, which contain three alpha-helices, adopt a common conformation named helix-turn-helix motives. Structural studies of three repeats in the vertebrate c-MYB have shown that both R2 and R3 are required for sequencespecific binding while R1 is not involved in the sequence recognition [30]. In each repeat, the three alpha-helices are stabilized by a hydrophobic core that includes three regularly spaced tryptophan residues. Within the $\mathrm{R} 2$ and $\mathrm{R} 3$ repeats, the $\mathrm{C}$-terminal helix is involved in the DNA specific recognition process and the protein insertion into the DNA major groove. It has been suggested that the recognition helix of R3 specifically interacts with the core of the MYB-binding sequence (MBS). In contrast, the R2 C-terminal helix is supposed to interact less specifically with adjacent nucleotides [31-33]. Finally, the $\mathrm{R} 3$ repeat has also been proposed to provide a platform for protein-protein interactions, especially with bHLH cofactors [24].

Mutations altering protein-protein interactions between any member of the ternary complex without affecting their inherent properties (DNA binding activities and/or stabilization of the complex) not only will be of significant value in terms of improving fundamental knowledge of such protein complexes but may also be useful to propose innovative engineering strategies to enhance the biosynthesis of specific secondary metabolites in plant system models. In grapevine, the broader regulatory impact of VvMYB5b compared to more specific transcription factors such as VvMYBA1 or VvMYBPA1 and 2 makes it as potential candidate for such engineering strategy [21]. In this study, we investigated the consequences of a single amino-acid substitution located on the third helix of the R2 domain on the transcriptional regulatory properties of VvMYB5b [21]. Based on structural homology studies with the c-MYB protein, we choose to replace a positively charged arginine in position 69 from the native protein $\left(\mathrm{VvMYB} 5 b^{\mathrm{R}}\right)$ by a neutral leucine (VvMYB5b $b^{\mathrm{L}}$ ). Effects of conformational changes on the DNA-binding and the trans-regulation properties of the mutated $\mathrm{VvMYB}_{\mathrm{V}} \mathrm{b}^{\mathrm{L}}$ protein were investigated in yeast and in grape suspension cells and compared to those of the native protein. $\mathrm{VvMYB}^{\mathrm{B}} \mathrm{b}^{\mathrm{R}}$ and VvMYB5b ${ }^{\mathrm{L}}$ capabilities to physically interact with the bHLH protein VvMYC1 were assessed using twohybrid assays in yeast. Finally, overexpression of VvMYB5b $b^{\mathrm{L}}$ in tobacco was performed to estimate the in planta impact of the mutation on the array of VvMYB5 $b^{R}$ target genes. Taken together, our results highlight the importance of dimerization between MYB and bHLH factors for the selectivity of target genes.

\section{Results}

\section{Structural model of VvMYB5b R2R3 domain}

The Vitis vinifera MYB5b gene encodes a MYB-like protein containing two imperfect repeats (R2R3) and an interaction domain ([D/E $\left.\mathrm{Lx}_{2}[\mathrm{R} / \mathrm{K}] \mathrm{x}_{3} \mathrm{Lx}_{6} \mathrm{Lx}_{3} \mathrm{R}\right)$ with bHLH protein partners [21,24,34] (Figure 1A). The alignment of the VvMYB5b sequence with MYB transcription factors already characterized in grape (VvMYB5a, VvMYBA1, and VvMYBPA1) confirms the 


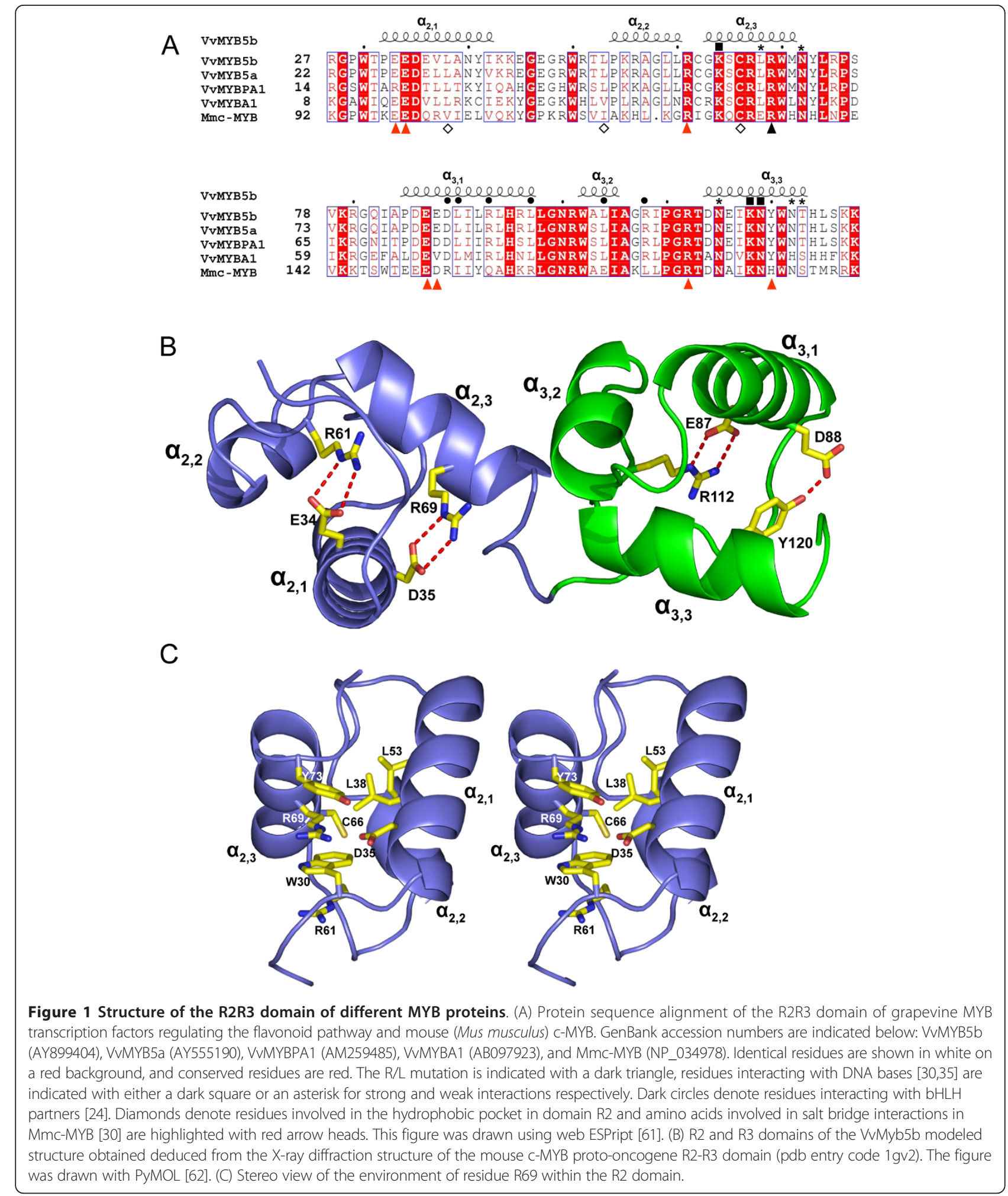

high sequence homology of the MYB domains (Figure $1 \mathrm{~A})$. The sequence identity remains very high $(46 \%)$ when compared with the R2 and R3 repeats of mouse cMYB, a protein with its $3 \mathrm{D}$ structure already characterized in its free state or in complex with DNA [30]. Groups of highly conserved residues have been assigned key roles in the structure and function of these proteins: a first group of residues located at the $\mathrm{C}$ - 
terminal parts of the R2 and R3 domains is involved in interactions with DNA. A second group, located at the $\mathrm{N}$-terminal part of domain $\mathrm{R} 3$, interacts with bHLH protein partners as described above [24,30,35]. Finally, a third group includes residues responsible for the ternary structure of the protein: in each domain, several charged residues establish salt bridges between $\alpha$-helices which maintain their relative orientations, whereas hydrophobic residues form a hydrophobic core buried within the three $\alpha$-helices [36].

A structural model of VvMYB5b was built (Figure 1B) using the crystallographic coordinates of the Mmc-MYB R2-R3 domain (pdb code: 1gv2) as starting model. The resulting model appears very close to the template model with a root-mean-square deviation (rmsd) of superimposed $\mathrm{C} \alpha$ of $0.89 \AA$ for 100 aligned residues. As visualized in Figure 1B, all four salt bridges observed in Mmc-MYB are strictly conserved in VvMYB5b and adopt the same conformations, with the exception, in domain R3, of the interaction D88-Y120, which is substituted by a D152-H184 interaction in the Mmc-MYB protein. Within domain $\mathrm{R} 2$, residue $\mathrm{R} 69$ is involved in a conserved salt bridge and was chosen as a target for single point mutation for the following reasons: (i) the salt bridge appears to be strictly conserved in all MYB sequences (Figure 1A) and does not interact with bHLH partners [24]; (ii) its counterpart in Mmc-MYB (R133) was shown to interact with phosphate groups of target DNA [30] to facilitate DNA binding; (iii) D35, the partner of R69 in the salt bridge, appears to be far enough from any other residue from the R2 domain C-terminal $\alpha$-helix to avoid establishing a new stabilizing interaction. In addition, R69 also takes part in the stacking of several side chains, i.e. R61, W30, R69 and Y73, which certainly participates to the 3D structure arrangement of the R2 domain (Figure 1C). A similar situation has been observed in Mmc-MYB with the residues R125, W95, R133 and H137.

Therefore, the arginine in position 69 of VvMYB5b was replaced by a leucine neutral residue. The resulting mutation, named R69L and located nearby the DNA Binding Domain (DBD), appeared likely to modify the interaction with the DNA backbone and the protein activity by disrupting the ternary structure of the transcription factor itself.

\section{The R69L mutation reduces VvMYB5b trans-activation capacity in yeast}

An assay was conducted to determine whether the R69L mutation affects VvMYB5b trans-activation properties in yeast. As shown in Figure 2, yeasts transformed with the $V v M Y B 5 b^{R}$ effector construct exhibited a 5 -fold increase in $\beta$-galactosidase activity compared to yeasts that express VvMYB5b ${ }^{\mathrm{L}}$. Nevertheless, VvMYB5b ${ }^{\mathrm{L}}$ was still

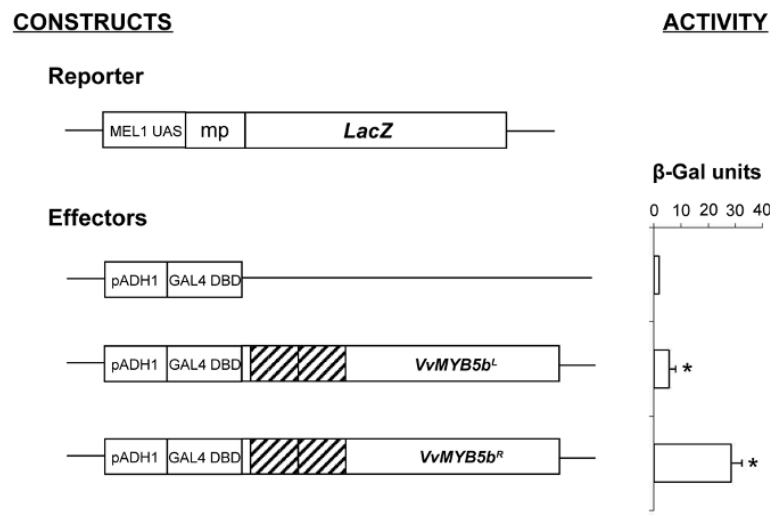

Figure 2 The single residue substitution R69L reduces VvMYB5b trans-activation capacity in yeast. $V V M Y B 5 b^{R}$ and VVMYB5 $b^{L}$ coding sequences were fused to GAL4 DNA Binding Domain (DBD) and their ability to activate $L a c Z$ reporter gene expression was quantified using $\beta$-galactosidase activity measurements. Each value is the mean \pm SD of two independent yeast transformations and each experiment included three measures (Student's $t$ test; ${ }^{*} P<0,05$ vs. negative control). Constructs are identified as indicated to the left of the figure. MEL1 UAS, Melibiose 1-GAL4 Upstream Activating Sequence; mp, minimal promoter; pADH1, Alcohol Dehydrogenase 1 promoter. Both MYB repetitions (i.e. R2 and R3 repeats) are indicated using dashed boxes.

functional despite a growth delay on solid selective medium (6 days) compared to VvMYB5b ${ }^{\mathrm{R}}$ recombinant yeasts that were able to develop 4 days after transformation (data not shown). Indeed, VvMYB5b ${ }^{\mathrm{L}}$ could activate $L a c Z$ expression 3 times more than the GAL4-DBD itself. These results indicate that (i) VvMYB5b can activate transcription in yeast and (ii) that the R69L substitution significantly reduces VvMYB5b transcriptional activities.

\section{VvMYB5 $b^{\mathrm{L}}$ no longer activates transcription of a flavonoid structural gene in grape cells}

As for many other MYB proteins, VvMYB5b requires co-expression of both bHLH and WDR protein partners, i.e. AtEGL3 (ENHANCER of GLABRA 3) and AtTTG1 respectively, to up-regulate target gene expression $[15,17,21,34]$. Thus, a dual luciferase assay was conducted to assess the effect of the R69L substitution on VvMYB5b ability to activate the $V v C H I$ promoter in grape cells, in the presence or the absence of bHLH and WDR proteins.

As shown in Figure 3, co-transformation with $\mathrm{VvMYB}_{\mathrm{V}} \mathrm{b}^{\mathrm{R}}$ effector plasmid and $V \nu C H I$ reporter construct, together with the WD40 protein AtTTG1, resulted in a 5-fold increase of luciferase activity, as compared to the control (reporter construct with AtTTG1). Presence of AtEGL3 increased the transcriptional activity of $\mathrm{VvMYB}^{\mathrm{R}} \mathrm{b}^{\mathrm{R}}$ up to 18 -fold. In contrast, same experiments with VvMYB5b ${ }^{\mathrm{L}}$ showed that 


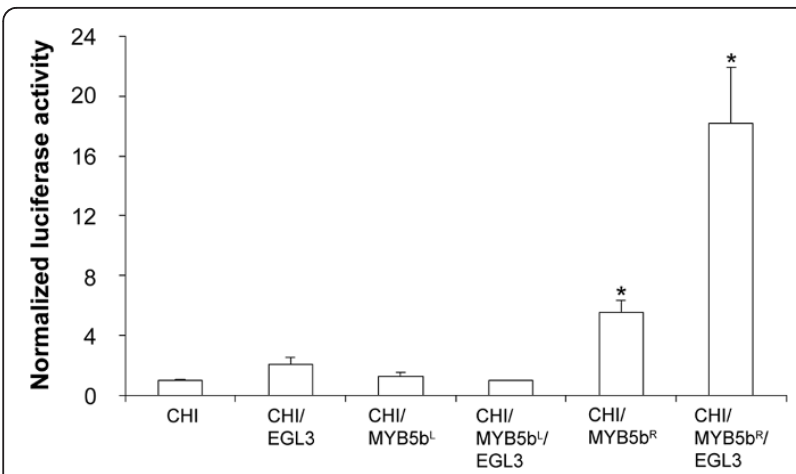

Figure 3 Unlike $V_{v M Y B 5 b^{R}}, V_{v M Y B 5} b^{L}$ is not able to activate $V v C H I$ promoter in grape cells. Results of transient expression after co-bombardments of cultured grape cells with the Firefly luciferase reporter gene fused to the $\mathrm{V} V \mathrm{CH}$ promoter and combinations of $V_{V M Y B 5} b^{R}$ or $V_{V M Y B 5} b^{L}$, together with AtEGL3 and AtTTG1. The normalized luciferase activity was calculated as the ratio between the Firefly and the Renilla luciferase (used as internal control) activity [63]. All bombardments included the WD40 protein AtTTG1 (GenBank accession number AJ133743). Values indicate the fold increase relative to the activity of the $\mathrm{V} v \mathrm{CH}$ promoter transfected without transcription factors. Each column represents the mean value $\pm \mathrm{SD}$ of three independent experiments (Student's $t$ test; ${ }^{*} P<0.05$ vs. Vv(HI alone).

VvMYB5b ${ }^{\mathrm{L}}$ was not able to activate $\mathrm{VvCHI}$ promoter in the presence of AtTTG1 (Figure 3). In the same way, co-transformation using $V v M Y B 5 b^{L}$ construct with AtEGL3 and AtTTG1 did not increase the luciferase activity. Altogether, these results show that, in grapevine cells, VvMYB5b ${ }^{\mathrm{L}}$ no longer displayed any transcriptional activation of the $\mathrm{V \nu CHI}$ promoter in the presence of the two imposed proteins from Arabidopsis, AtEGL3 and AtTTG1.

\section{The R69L substitution abolishes VvMYB5b interaction with a bHLH partner}

A yeast two-hybrid assay was conducted to investigate the ability of $\mathrm{VvMYB} 5 \mathrm{~b}^{\mathrm{L}}$ to physically interact with a putative Vitis bHLH partner. Our results (Figure 4) confirmed that VvMYB5 $b^{\mathrm{R}}$ could interact with VvMYC1, as previously described [22]. On the other hand, VvMYB5b ${ }^{\mathrm{L}}$ was not able to form dimers with VvMYC1 to activate $L a c Z$ expression.

In addition, the ability of the $\operatorname{VvMYB} 5 \mathrm{~b}^{\mathrm{R}}$ and VvMYB5 $b^{L}$ proteins to bind MBS (MYB binding sites) cis-elements was evaluated using EMSA (Electrophoretic Mobility Shift Assay). Both proteins were synthesized by an in vitro transcription and translation assay and biotinylated protein bands were detected by a chemiluminescent assay (see additional file 1). The results showed that both proteins accumulated in identical ways and are not degraded. However, neither native VvMYB5b ${ }^{R}$ nor mutated VvMYB5 $b^{\mathrm{L}}$ could bind MBS sequences

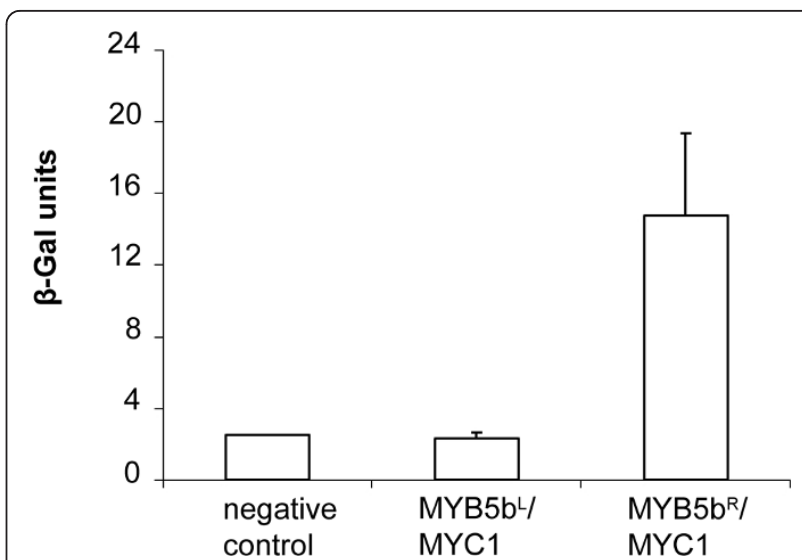

Figure $4 \mathrm{VvMYB}^{\mathrm{L}} \mathrm{b}^{\mathrm{L}}$ loses its ability to physically interact with the bHLH transcription factor VvMYC1 in yeast. Yeast twohybrid experiments have been performed by co-transformation with VVMYB5b $b^{R}$ or $V_{V M Y B 5} b^{L}$ proteins fused to GAL4 Activation Domain, and VVMYC1 fused to GAL4 DNA Binding Domain. Transformed yeasts were selected on SD-LeuTrp' medium and tested for LacZ activation. $\beta$-Galactosidase activity results are the mean of three measurements of three independent yeast clones. Negative twohybrid control refers to the control provided by the manufacturer. Error bars indicate SD.

using EMSA. Likewise, none of both proteins $\left(\mathrm{VvMYB}^{\mathrm{b}} \mathrm{b}^{\mathrm{L}}, \mathrm{V}_{\mathrm{vMYB}} 5 \mathrm{~b}^{\mathrm{R}}\right.$ ) was able to bind the $\mathrm{VvCHI}$ promoter sequence in yeast one-hybrid experiments (data not shown).

Flavonoid biosynthesis genes are differentially expressed in flowers of $V v M Y B 5 b^{R}$ or $V v M Y B 5 b^{L}$ transgenic tobacco lines

$V v M Y B 5 b^{R}$ and $V v M Y B 5 b^{L}$ coding sequences were ectopically expressed in tobacco plants under the control of the $35 S$ constitutive promoter. Three T2 homozygous independent lines tested for each construct were used for further investigations. Analyses were only carried out on flowers since no phenotypic differences were detected at the vegetative level. Corolla and stamens of $35 S:: V v M Y B 5 b^{R}$ tobacco flowers exhibited a strong red pigmentation and a purple color, which was associated with higher anthocyanidin accumulation not observed in control plants [21]. By contrast, flowers of tobacco plants over-expressing $V v M Y B 5 b^{L}$ did not exhibit a greater accumulation in anthocyanidin in both flower organs (Figure 5A) and no significant changes of anthocyanin content were observed in corolla and stamens (see additional file 2). To tentatively explain these phenotypes, transcript abundances of three tobacco flavonoid biosynthetic genes (chalcone synthase (NtCHS), dihydroflavonol 4-reductase (NtDFR) and anthocyanidin synthase (NtANS)) were monitored by quantitative RTPCR (qRT-PCR) to identify in planta target structural genes of VvMYB5b together with the impact of the 

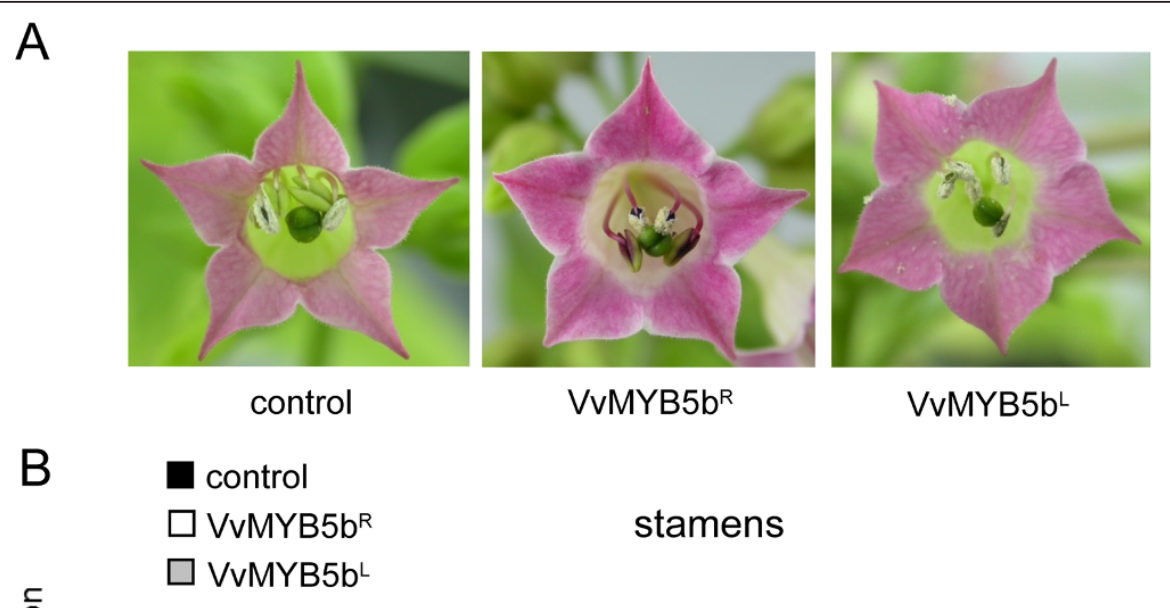

stamens
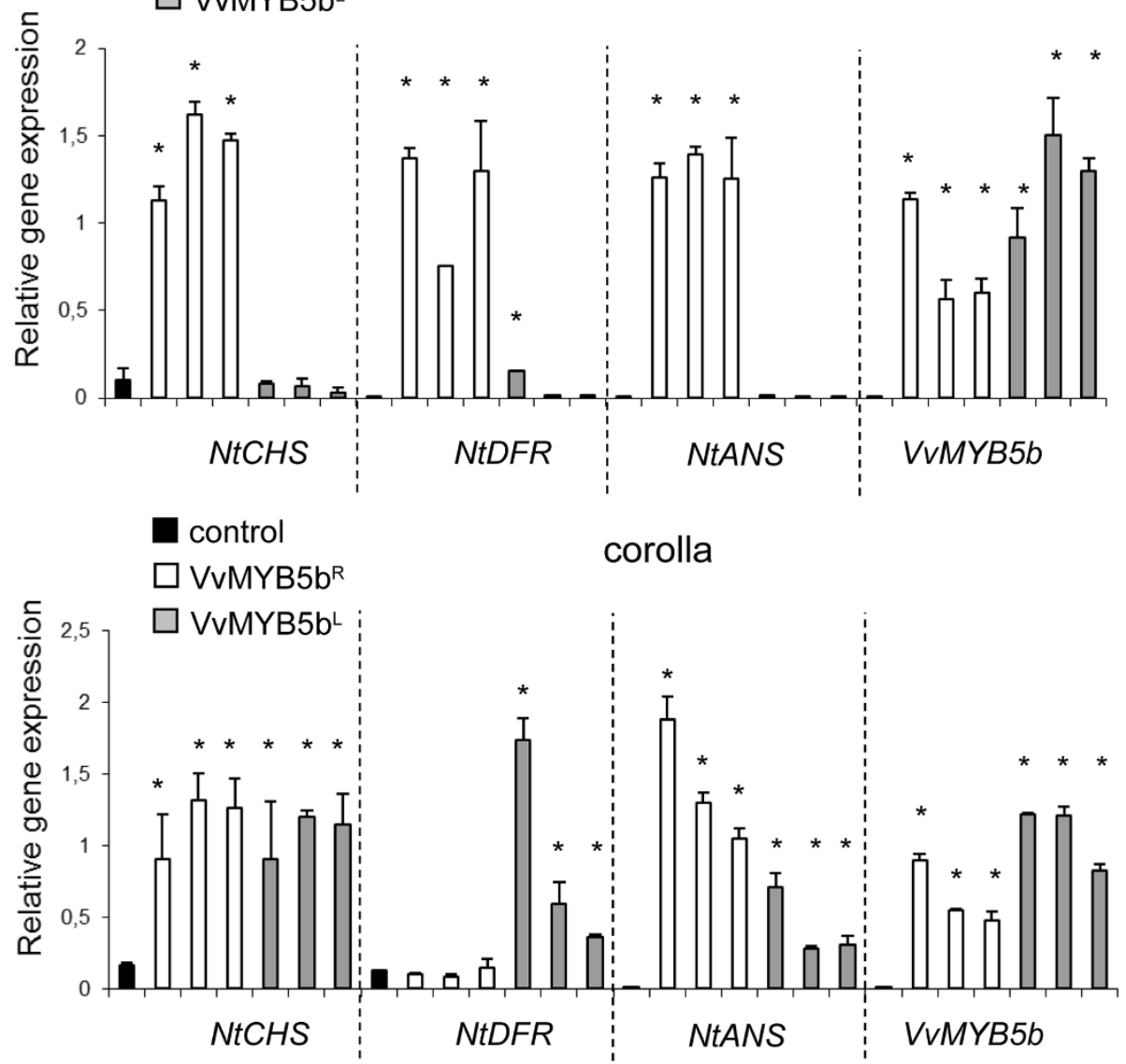

Figure 5 Analysis of $V v M Y B 5 b^{R}$ and $V v M Y B 5 b^{L}$ ectopic expression effect in tobacco plants flowers. (A) Flowers of $V V M Y B 5 b^{R}$ overexpressing plants showed an intense red coloration of petals and stamens, compared to control and $V v M Y B 5 b^{L}$ transgenic flowers. (B) Real time quantitative RT-PCR analysis of NtCHS (chalcone synthase), NtDFR (dihydroflavonol reductase) and NtANS (anthocyanidin synthase) transcript abundance in stamens and corollas. Gene expression is shown relative to NtUbiquitin transcript levels in each sample. Results are presented for three independent transgenic lines overexpressing either $V V M Y B 5 b^{R}$ or $V V M Y B 5 b^{L}$, and compared to control plants. $V V M Y B 5 b$ indicate transgene transcript levels. Each bar represents the mean \pm SD of three replicates ( $P<0.05$ vs. control plants according to the ANOVA).

mutation on the expression of these same genes. As shown in Figure 5B, none of these genes was expressed in stamens of control plants, which is consistent with the fact that anthocyanins are not normally synthesized in this particular tissue. As previously described in [21], overexpression of $V v M Y B 5 b^{R}$ induced higher transcription of NtCHS, NtDFR and NtANS mRNAs together with anthocyanin accumulation in stamens. In corolla cells, NtDFR expression did not appear to be affected but an increase in CHS and ANS transcript abundances 
was observed and correlates with an anthocyanin content significantly higher than in control plants.

In contrast, $V v M Y B 5 b^{L}$ overexpression did not enhance NtCHS, NtANS and NtDFR transcript abundances in stamens although expression levels of transgene for both constructs $\left(35 S:: V v M Y B 5 b^{R}\right.$ and $35 S::$ $\left.V v M Y B 5 b^{L}\right)$ were the same. However, VvMYB5b ${ }^{\mathrm{L}}$ appeared to retain some trans-activation activity in corolla where $N t C H S$ and $N t A N S$ transcripts abundance was significantly higher than in wild-type plants. In addition, corolla cells expressing VvMYB5b ${ }^{\mathrm{L}}$ accumulated significantly more $N t D F R$ transcripts than control and $35 S:: V v M Y B 5 b^{R}$ plants. Surprisingly, this increase in flavonoid genes expression did not affect the anthocyanin concentration in $V v M Y B 5 b^{L}$ corolla (see additional file 2). Altogether, these results indicate that (i) VvMYB5 $b^{\mathrm{L}}$ has severely lost its trans-activation ability in stamens whereas this same regulatory protein was still active in corolla; (ii) VvMYB5 $b^{\mathrm{L}}$ might have new regulatory functions in corolla cells as its overexpression induced the up-regulation of the NtDFR that was not observed in $35 S:: V v M Y B 5 b^{R}$ plants.

\section{Discussion}

Over the past two decades, an increasing number of studies investigating the transcriptional regulation of the flavonoid pathway have been published (reviewed in $[8,10])$. Most of them emphasized the pivotal role of MYB transcription factors in the control of this metabolic pathway. More recently, new findings highlighted the importance of a multi-protein complex involving MYB proteins with bHLH and WDR partners in the coordination of the transcriptional regulation of flavonoid biosynthetic genes. Nevertheless, the way in which this multi-protein complex specifically regulates expression of genes depending on the tissue, the developmental stage or the environmental conditions is not fully understood yet.

The structure of the MYB DNA-Binding Domain (DBD) interacting with a double DNA strand has already been investigated in several models [37-39]. These studies have shown that the third helices of both $\mathrm{R} 2$ and $\mathrm{R} 3$ are involved in the recognition of a specific DNA consensus sequence [30,40]. In Mmc-MYB, K128, positioned in the R2 domain, together with K182 and N183 positioned in the R3 domain, were identified as key residues in the 'recognition' of the specific nucleotide sequence AACNG, the so-called 'MYB Binding Site' $[30,41]$. Later, the same authors demonstrated that the methylene chain of residue R133 delimits, with three other amino acids (V103, C130 and I118), a cavity in the centre of a hydrophobic core that may play a role in the conformational stability of the R2 domain [36]. For instance, an amino acid substitution (V103L) within this cavity reduces the conformational flexibility of the $\mathrm{R} 2$ domain and thereby significantly decreases specific MYB-DNA binding activity and trans-activation. The model of the VvMYB5b R2R3 domain illustrated in Figure $1 \mathrm{~B}$ shows that the $\mathrm{R} 69$ residue is, like its counterpart R133 in Mmc-MYB, involved in the formation of a salt bridge that may participate in the stabilization of the protein [30]. The impact of salt bridges formation in the activity of such transcription factor is poorly understood, but the few available studies suggest that they may influence both DNA binding affinities and transactivation properties of transcription factors. Disruption of the salt bridge by amino acid substitution affected the CRP (cAMP Receptor Protein) protein activity and led to a reduction of the $L a c$ promoter trans-activation, without affecting its DNA binding affinity $[42,43]$. This reduction is attributed to an alteration of the interaction with the $\alpha$-subunit of RNA polymerase. In our study, R69 was substituted by a leucine residue, and we demonstrated that this single residue mutation in the third helix of the $\mathrm{R} 2$ repeat could modify the protein interaction properties of VvMYB5b together with its DNA binding affinities.

\section{The R69L substitution affects trans-activation properties of VvMYB5b}

In yeast, we found that VvMYB5b $b^{\mathrm{L}}$ effector construct fused to yeast GAL4-DBD was barely able to increase the expression of reporter genes. One can make the assumption that the amino acid substitution within R2

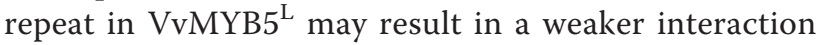
between this protein and yeast general co-activators of the RNA polII complex. Indeed, transcription factors act in several ways through protein interactions to enhance the expression of a target gene. Activators interact with chromatin remodelling factors, general transcription factors (GTFs) of the RNA polII pre-initiation complex, and can also affect initiation of the transcription and elongation $[44,45]$. The decrease of transactivation properties of VvMYB5b caused by the mutation, in yeast, can be explained by a decrease of its ability to recruit the yeast GTFs.

In eukaryotic transcription factors, DNA-Binding Domains and Activation/Repression domains are thought to be spatially independent. The yeast twohybrid technique is based on this concept [46]. Based on our results (Figure 2), these two domains seem to be intimately dependent, as previously shown for some MYB transcription factors. In the c-MYB protein for instance, the $\mathrm{C}$-terminal negative regulation domain can interact with the R2R3 N-terminal domain to alter its intrinsic properties [47]. Likewise, in C1, a MYB transcription factor promoting anthocyanin accumulation in maize, the R2R3 domain seems to interact with the C- 
terminal region to keep the protein inactive in the absence of its bHLH partner [25].

Although VvMYB5b works in yeast as a strong transcriptional activator, it requires in grape cells, as does VvMYBA, at least one bHLH partner to be fully functional $[15,21,22$, present work]. In this study, $\mathrm{VvMYB}^{\mathrm{L}} \mathrm{b}^{\mathrm{L}}$ was not able to activate $\mathrm{V \nu CHI}$ promoter in grape cells despite the co-expression of both bHLH and WDR. In addition, we show that, unlike VvMYB5b ${ }^{\mathrm{R}}$, VvMYB5b ${ }^{\mathrm{L}}$ did not interact with VvMYC1 in yeast [22]. Taken together, these results suggest that the amino acid substitution clearly has an impact on the proteinprotein interaction selectivity and subsequently on the trans-activation properties of the regulatory complex as well.

\section{The R69L mutation modifies the in vivo selectivity of VvMYB5b for protein partners}

Overexpression experiments in tobacco suggest the presence of different regulatory mechanisms in stamens and corollas, with regard to flavonoid pathway genes expression. First, none or little expression was observed for the NtCHS, NtANS and NtDFR genes in stamens of control plants. This suggests the absence of an efficient regulatory complex in this tissue or the lack of at least one component of the system. However, in corollas of control plants, a baseline expression was detected for the same structural genes on the same control plants supporting the idea of a pre-existing transcriptional network regulating the accumulation of anthocyanins in these floral organs.

In $35 S:: V v M Y B 5 b^{R}$ transgenic tobacco stamens, it appears that the presence of the native $V_{v M Y B} b^{R}$ protein and its interaction with endogenous pre-existing protein partner(s) leads to the activation of the entire anthocyanin biosynthetic pathway ([21]; Figure 6). In corollas, the absence of NtDFR upregulation observed in $35 S:: V v M Y B 5 b^{R}$ plants might be explained by the lack of interaction between $\mathrm{VvMYB}_{\mathrm{V}} \mathrm{b}^{\mathrm{R}}$ and a specific protein partner different from the one required for NtANS and NtCHS genes expression (termed Z in Figure 6). Another hypothesis may involve the presence of two distinct NtDFR genes in stamen and corolla, respectively. This alternative explanation cannot be totally ruled out but seems unlikely, taking into account the fact that the primers used in this study have been designed to amplify the two DFR genes identified to date in the tobacco genome.

In the $35 S:: V v M Y B 5 b^{L}$ plants, the clearly different behavior of VvMYB5b $b^{L}$ in stamen and corolla cells regarding gene activation capabilities supports the hypothesis of the presence of various protein partners in these tissues. In addition, the induction of $\mathrm{NtCHS}$,
NtANS and NtDFR genes expression observed in corolla indicates that VvMYB5b ${ }^{\mathrm{L}}$ can efficiently bind DNA in this tissue. Thus, in stamens, $V_{v M Y B} b^{L}$ might fail to interact with the endogenous co-partner(s), and thus not induce the expression of the NtCHS, NtANS and $N t D F R$ genes (Figure 6). The situation is clearly different in corollas where the presence of VvMYB $5 b^{\mathrm{L}}$ leads to the induction of all genes studied, indicating that the mutated protein can interact with the array of endogen-

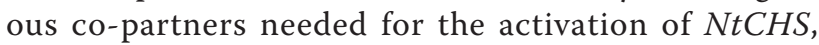
$N t A N S$ and NtDFR genes expression. In addition, the induction of NtDFR expression in corolla cells, which is not observed in the presence of $V_{v M Y B} b^{R}$, indicates that the structural changes linked to the mutation have now allowed the interaction with the specific partner required for $N t D F R$ gene expression (Figure 6). Thus, taken together, these results indicate that the R69L substitution modifies the interaction capabilities of VvMYB5b with its putative protein partners, which subsequently impacts on the regulation of target genes expression.

In maize, amino acid substitutions within the DNA binding domain of the MYB transcription factor $\mathrm{ZmP1}$ also has a strong influence on the cooperative effect of $\mathrm{ZmP1}$ with its partners [25]. Indeed, $\mathrm{ZmP1}$ does not require the interaction with the $\mathrm{bHLH}$ protein $\mathrm{R}$ to transactivate the DFR gene but fails to transactivate the $b z 1$ gene encoding UDP-glucose:flavonoid 3-O-glucosyltransferase [24,25]. Mutation of $\mathrm{ZmP1}$ within the DBD facilitates $\mathrm{ZmP1}$ interaction with $\mathrm{R}$, which in turn allows the binding of the complex to the promoter region of $b z 1$ gene.

Further investigations will be needed to ascertain the model presented in Figure 6, such as the identification of different bHLH or WDR partners in both tobacco corollas and stamens. Co-expression of two different $b H L H$ genes has already been demonstrated in petunia flowers, where AN1 and Jaf13 are preferentially expressed in corolla and stamens, respectively $[11,48]$ ). Likewise, in snapdragon flowers, the MYB transcription factors Rosea1, Rosea2 and Venosa control anthocyanin biosynthesis by differentially interacting with the bHLH partners Mut and Delila in the different floral organs [49]. In the same way, the Gerbera hybrida bHLH protein GMYC1 is thought to control the expression of the GhDFR gene in corolla and carpel tissues, whereas an alternate GMYC1-independent regulatory mechanism may exist in pappus and stamens [50]. These studies indicate that different bHLH transcription factors may be co-expressed in the different tissues of tobacco flowers. However, for this plant species, only one MYB transcription regulating the flavonoid pathway factor has been characterized so far [51]. 


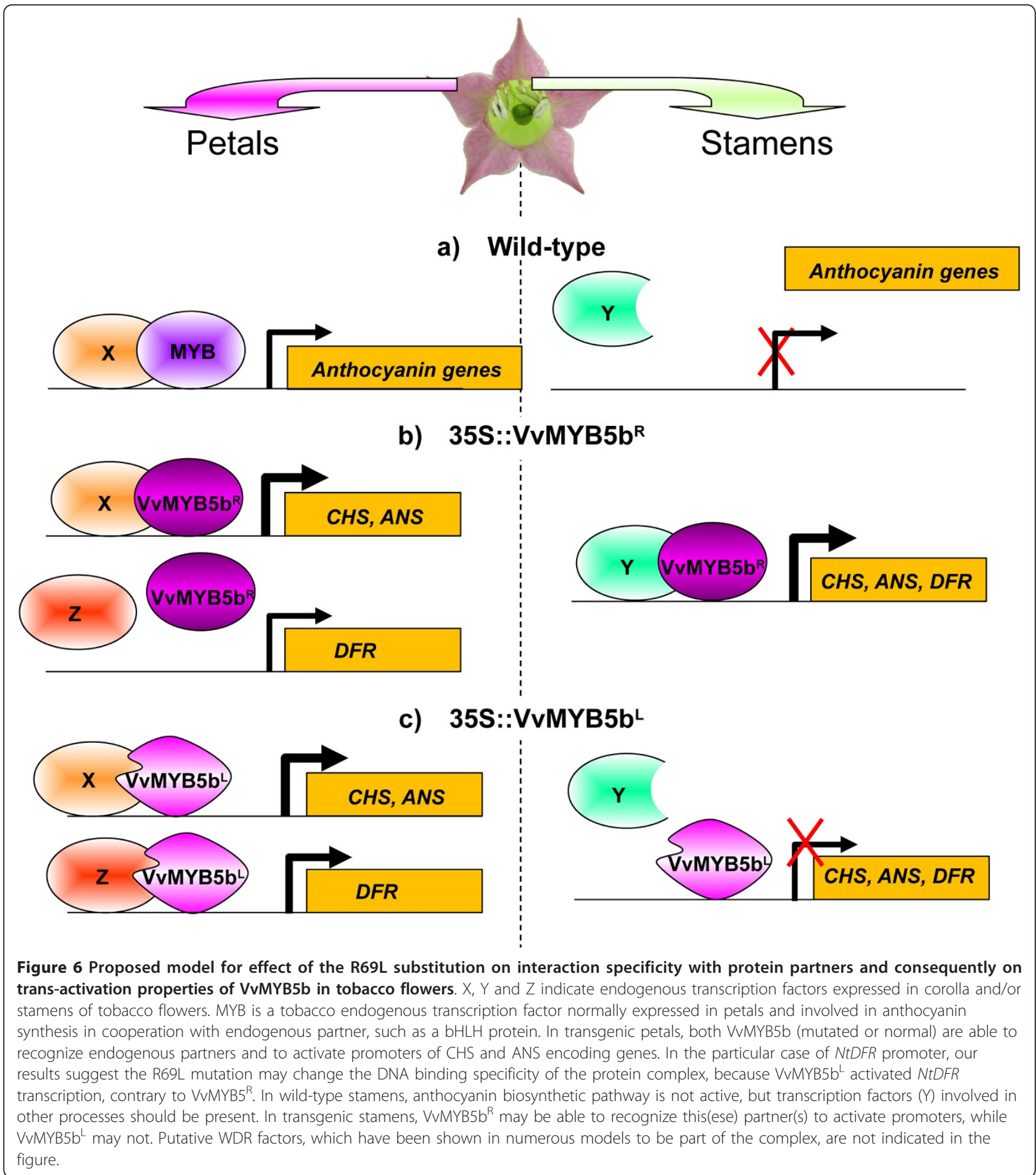

\section{Conclusions}

The amino acid substitution in position 69 was expected to have an impact on the DNA-binding activity of VvMYB5 $b^{\mathrm{L}}$, as previously described for the c-MYB protein $[30,52]$. According to our results, neither native VvMYB $5 b^{\mathrm{R}}$ nor mutated $\mathrm{VvMYB}^{\mathrm{L}} \mathrm{b}^{\mathrm{L}}$ were able to bind
MBS sequences in EMSA experiments. However, $\mathrm{VvMYB}^{\mathrm{B}} \mathrm{b}^{\mathrm{R}}$ did activate the $V \nu C H I$ promoter when coexpressed with the co-factors AtEGL3 (bHLH) and AtTTG1 (WDR) in grapevine cells (Figure 3), but was not able to bind the same sequence in yeast one-hybrid experiments. These results indicate that VvMYB5b 
needs its protein partner(s) to bind DNA and that EMSA and yeast one-hybrid methods are not appropriate to investigate the ability of $\mathrm{VvMYB} 5 \mathrm{~b}^{\mathrm{R} / \mathrm{L}}$ to bind target sequences. Finally, the upregulation of the NtCHS, NtANS and NtDFR genes observed in $35 \mathrm{~S}:: V v M Y B 5 b^{L}$ tobacco plants is consistent with the presence of a functional VvMYB5b ${ }^{\mathrm{L}}$ protein. Thus, VvMYB5b $\mathrm{b}^{\mathrm{L}}$ appears still able to recognize and bind DNA, even though further investigations will be needed to ascertain the direct or indirect role of residue R69 in the DNA binding properties of VvMYB5b.

In summary, this work describes the structural and biological consequences of a single amino acid change on both the dimerization and the DNA binding properties of a grapevine MYB transcription factor. These two functions appear related, as the conformation of the R2R3 domain, that regulates DNA affinity and binding, can be modified after interactions with protein partners. As a consequence, the array of target genes of a given MYB factor may vary depending on the protein partner involved.

\section{Methods}

\section{Plant Material}

Seeds from wild type and homozygous T2 generation of transgenic tobacco plants (Nicotiana tabacum cv Xanthi) were sterilized in $2.5 \%$ potassium hypochlorite, $0.02 \%$ Triton X-100 for $10 \mathrm{~min}$, and washed five times with sterile water. After cold treatment at $4^{\circ} \mathrm{C}$ for $48 \mathrm{~h}$, seeds were germinated on MS medium [53] containing $3 \%(\mathrm{w} / \mathrm{v})$ sucrose, supplemented with $200 \mu \mathrm{g} / \mathrm{ml} \mathrm{kana}-$ mycin for transgenic plants, at $25 / 20^{\circ} \mathrm{C}$ under a $16 \mathrm{~h}$ light/8 h dark regime. Eight weeks after germination, in vitro grown plantlets were transferred to soil into individual pots and cultivated in a growth chamber under the same environmental conditions. The suspension culture of grapevine Chardonnay (Vitis vinifera L.) petiole callus was grown in grape Cormier medium as described in [54], at $25^{\circ} \mathrm{C}$ in darkness on an orbital shaker at $90 \mathrm{rpm}$.

\section{VvMYB5b R2R3 domain modeling}

$V v M Y B 5 b$ was modeled starting from the crystal structure of the mouse c-MYB R2R3 domain (PDB code 1GV2, Tahirov et al., unpublished result) using the SWISSMODEL server [55]. The obtained model was further checked using the molecular graphics program COOT [56]. Misorientation of a few side chains has been manually corrected and the full model regularized by molecular dynamics simulated annealing, using the standard protocols implemented with the Phenix software [57].

\section{Generation of the VvMYB5b $b^{\mathrm{L}}$ substitution and tobacco stable transformation}

The $V v M Y B 5 b$ cDNA sequence (gene accession AY899404) used in this study was previously inserted in the pGEM-T-Easy cloning vector (Promega, Madison, WI) [21]. The R69L substitution was introduced into the cloned $V v M Y B 5 b$ using the QuickChange site-directed mutagenesis kit (Stratagene). Reactions were carried out using the following primer pair: 5'-CAAGAGCTGTCGCCTCCTCTGGATGAACTACCTC-3' (sense) and 5'-GAGGTAGTTCATCCAGAGGAGGCGACAGCTCTTG-3' (antisense). The presence of the introduced mutation in the cDNA was confirmed by DNA sequencing. The native $V v M y b 5 b^{R}$ and $V v M Y B 5 b^{L}$ full length cDNAs were then cloned between the XbaI/ $S a c$ I restriction sites of the pGiBin 19 binary vector between the $35 \mathrm{~S}$ promoter of the cauliflower mosaic virus and the nopaline synthase (nos) poly(A) addition site, as described in [21]. Both constructions were introduced into Agrobacterium tumefaciens LB4404 host strain. Tobacco was transformed and regenerated according to the leaf discs method [58]. Selection of the primary transformants was carried out on MS medium containing $200 \mu \mathrm{g} / \mathrm{ml}$ kanamycin. Presence of the transgene was confirmed by PCR on genomic DNA extracted from leaves of primary transformants, according to the manufacturer instructions (DNeasy Plant Mini Kit, Qiagen). Seeds of self-fertilized T1 and T2 lines were collected and single-copy insertion T2 lines were selected based on a Mendelian segregation ratio.

\section{RNA extraction and gene expression analysis}

Total RNA was isolated from wild-type and transgenic tobacco flower tissues according to [59]. At least three flowers were randomly collected per plant, and two plants selected for each lines: control (untransformed plants), $35 S:: V v M Y B 5 b^{R}$ and $35 S:: V v M Y B 5 b^{L}$. One $\mu \mathrm{g}$ of total RNAs was reverse transcribed with oligo $(\mathrm{dT}) 12-18$ in a $20 \mu \mathrm{l}$ reaction mixture using the Moloney murine leukemia virus (M-MuLV) reverse transcriptase (RT) according to the manufacturer's instructions (Promega, Madison, WI). Transcript levels of NtCHS, NtF3H and $N t D F R$ endogenous genes and the transgene $V v M Y B 5 b^{R / L}$ were measured by real-time quantitative RT-PCR, using SYBR Green on an iCycler $i Q^{\circledR}$ (Bio$\mathrm{Rad})$ according to the procedure described by the supplier. PCR reactions were performed in triplicate using $0.2 \mu \mathrm{M}$ of each primer, $5 \mu \mathrm{l}$ SYBR Green mix (Bio-Rad) and $0.8 \mu \mathrm{l}$ DNAse treated cDNA in a final volume of 10 $\mu$ l. Negative controls were included in each run. PCR conditions were: initial denaturation at $95^{\circ} \mathrm{C}$ for $90 \mathrm{~s}$ followed by 40 cycles of $95^{\circ} \mathrm{C}$ for $30 \mathrm{~s}, 60^{\circ} \mathrm{C}$ for $1 \mathrm{~min}$. Amplification was followed by melting curve analysis to check the specificity of each reaction. Data were normalized according to the NtUbiquitin gene expression levels and calculated with a method derived from the algorithms outlined by [60]. Statistical analysis of the data was performed by analysis of variance (ANOVA) test 
using Sigma-Plot software. Sequences of the primers used for quantitative RT-PCR are indicated in Table 1. Two highly homologous sequences encoding DFR were used to design primers for real-time quantitative RTPCR experiments in tobacco (accession numbers: EF421430 and EF421429).

\section{Co-transfection experiments and dual luciferase assays} $V v M y b 5 b^{R}$ and $V v M y b 5 b^{L}$ full length cDNAs were amplified by PCR using the Phusion ${ }^{\mathrm{TM}}$ High-Fidelity DNA polymerase (Finnzymes) with oligonucleotides introducing the BamHI (5'-TAATGGATCCATGAGGAATGCATCCTCA-3') and SalI (5'-TAATGTCGACTCAGAACCGCTTATCAGGTTG-3') restriction sites (indicated in italics), and cloned in the pDH5 vector (kindly given by Pr M. Hernould, Bordeaux, France), a derivative from the pUC18 vector, that allows constitutive transient expression of the transgene. Integrity of each coding sequence was verified by sequencing (MWG, France) using the pDH5F (5'-CCCACTATCCTTCGCAAG-3') and the pDH5R (5'CTAATTCCCTTATCTGGGAA-3') primers. Transient co-transfection experiments of grapevine suspension cells and dual-luciferase assays were carried out as previously described in [17].

\section{Beta-galactosidase assay in yeast}

$V v M y b 5 b^{R}$ and $V v M y b 5 b^{L}$ cDNAs were amplified by PCR using the Phusion ${ }^{\mathrm{TM}}$ High-Fidelity DNA polymerase (Finnzymes) using oligonucleotides introducing the $B a m H I$ restriction site (indicated in italics) at the $5^{\prime}\left(5^{\prime}\right.$ TAATGGATCCAGATGAGGAATGCATCCTCA-3') and 3' (5'-TAATGGATCTCAGAACCGCTTATCAGGTTG-3') ends. After enzymatic digestion, PCR fragments were introduced into the pGBKT7 vector (Clontech, BD Bioscience), in fusion with the GAL4 DNA Binding Domain (DBD) coding region, under the control of the $A D H 1$ promoter. pGBKT7 vector carries the $\mathrm{Kan}^{\mathrm{R}}$ for selection in $E$. coli and the TRP1 nutritional marker for yeast selection. The yeast strain AH109 was independently transformed with pGBKT7,
pGBKT7-VvMYB5b $b^{R}$, or pGBKT7-VvMYB5b $b^{L}$ using the PEG/LiAc method, based on the manufacturer's instructions. Transformants were selected on synthetic dropout (SD) media lacking tryptophan (SD-Trp ${ }^{-}$) or histidine, adenine, and tryptophan (SD-His ${ }^{-} \mathrm{Ade}^{-} \mathrm{Trp}^{-}$). In parallel, positive and negative controls of interaction, provided by the manufacturer, have been performed (BD Matchmaker ${ }^{\mathrm{TM}}$ Library Construction \& Screening Kit, Clontech, BD Bioscience). As LacZ constitutes the fourth reporter gene of this system, $\beta$-galatosidase activity was monitored in recombinant yeasts grown on selective medium. $\beta$-galactosidase assays with the ONPG $(\mathrm{O}$ nitrophenyl- $\beta$-D-galactopyranoside) substrate were performed following the manufacturer instructions. Relative $\beta$-galactosidase activity was obtained after normalization with the optical density at $600 \mathrm{~nm}$.

\section{Yeast two-hybrid assay}

$V v M Y B 5 b^{R}$ or $V v M Y B 5 b^{L}$ coding regions were fused to the GAL4 Activation Domain (AD), and the coding sequence of $V v M Y C 1$ was fused to the GAL4-DBD. Because of its intrinsic ability to activate transcription in yeast, VvMYB5b ${ }^{R}$ has not been fused to GAL4-DBD, and consequently the reciprocal combinations were excluded from the two-hybrid assay. $V v M y b 5 b^{R}$ and $V v M y b 5 b^{L}$ cDNAs were amplified by PCR using the Phusion $^{\mathrm{TM}}$ High-Fidelity DNA polymerase with specific primers containing anchors: F, 5'-TTCCACCCAAGCAGTGGTATCAACGCAGAGTGG-3' and R, 5'GTATCGATGCCCACCCTCTAGAGGCC-

GAGGCGGCCGACA-3' which allow recombination in the linear plasmid pGADT7-Rec when introduced in yeast. Resulting construct carrying $\mathrm{Amp}^{\mathrm{R}}$ and $L E U$ selective characteristics allows expression of a GAL4 Activation Domain (AD)-VvMYB5b fusion protein. The $V v M Y C 1$ coding sequence (gene accession EU447172) was cloned into the pGBKT7 vector between EcoRI and PstI restriction sites [22]. The two-hybrid experiment was conducted using the Clontech BD Matchmaker ${ }^{\mathrm{TM}}$ Library Construction \& Screening Kit (BD Bioscience) according to the manufacturer's instructions. Yeast

Table 1 Primers used for real-time quantitative RT-PCR analysis.

\begin{tabular}{llll}
\hline Gene & Accession & Sequence $\left(\mathbf{5}^{\prime} \mathbf{- 3}\right.$ ) & Amplified fragments size (bp) \\
\hline VVMYB5b & AY899404 & F: GCCATGACTTCCACGTCTG & 115 \\
\hline NtCHS & R: CATTGCAGGGTGTTGAGCC & 126 \\
\hline NtANS & F: GGTTGGGAACTACTGGTG & 226 \\
\hline NtDFR & R: CCCACAATATAAGCCCAAGC & 116 \\
\hline NtUbiquitin & F: TCCATCTGGCCTAAAATCCCT & \\
& R: AACGCCAAGTGCTAGTTCTGG & 138
\end{tabular}


strain AH109 was transformed with pGBKT7-VvMYC1 construct, $V v M Y B 5 b^{R}$ and $V v M y b 5 b^{L}$ PCR products and the effector plasmid pGADT7-Rec, as described in [22]. Transformants were selected on SD- Trp Leu medium, to make sure that both effector plasmids were indeed integrated to yeast. Transcriptional activation of the reporter gene $L a c Z$ was evaluated by monitoring $\beta$ galactosidase activity.

\section{Additional material}

\section{Additional file 1: Detection of the in vitro synthesized VvMYB5b $b^{\mathrm{R} / \mathrm{L}}$} proteins. Both proteins were produced by the in vitro transcription and translation method with the TnT T7 quick system for the PCR DNA system (Promega, Charbonnières, France) according to the manufacturer's instruction. The coding sequences were amplified with Turbo-Pfu (Stratagene) using the following primers pairs: F, 5'-

AGATCCTAATACGACTCACTATAGGGAGCCACCATGAGGAATGCATCCTCAGCA and $R, 5^{\prime}-(T)_{32}$ TCAGAACCGCTTATCAGGTTG. The PCR products were used as template. A $5 \mu$ aliquot of the reagent was used for SDS-PAGE. Separated proteins were transferred onto a nitrocellulose membrane and detected using the Transcend non-radioactive translation detection system (Promega, Charbonnières, France). MW in KDa corresponds to the Page ruler prestained \#SM0671 protein ladder (Fermentas).

Additional file 2: Anthocyanin contents in flowers of control and transgenic plants. Anthocyanin pigments were extracted with $1 \% \mathrm{HCl}$ in methanol in the dark. The anthocyanin concentration is expressed as the absorbance units at $530 \mathrm{~nm}$ per gram of fresh tissue weight. Data are the mean of three replicates, and results from two independent transgenic lines are indicated. ND: not detected. Asterisk indicates values that significantly differ from the control $(P<0.05$; student's $t$ test)

\section{Acknowledgements}

We greatly thank Pr. Serge Delrot for critical reading of the manuscript.

\section{Author details}

'Univ. de Bordeaux, Institut des Sciences de la Vigne et du Vin (ISW), UMR 1287 Ecophysiologie et Génomique Fonctionnelle de la Vigne (EGFV), 210 Chemin de Leysotte, 33882 Villenave d'Ornon, France. ${ }^{2}$ INRA, ISW, UMR 1287 EGFV, 33882 Villenave d'Ornon, France. ${ }^{3}$ ENITAB, ISW, UMR 1287 EGFV, 33882 Villenave d'Ornon, France. ${ }^{4}$ Department of Horticulture, Oregon State University, Corvallis, Oregon 97331, USA. ${ }^{5}$ Dienstleistungszentrum Landlicher Raum (DLR) Rheinpfalz, Breitenweg 71, Viticulture and Enology group, D67435 Neustadt/W, Germany. ${ }^{6}$ Fachhochschule Bingen, Berlinstr. 109, 55411 Bingen am Rhein, Germany. 'Université de Toulouse, INP-ENSAT Toulouse, Génomique et Biotechnologie des Fruits, Avenue de l'Agrobiopole BP 32607, 31326 Castanet-Tolosan, France. ${ }^{8}$ Chimie et Biologie des Membranes et des Nanoobjets, UMR CNRS 5248, Bâtiment B14bis, Allée Geoffroy de Saint Hilaire, Université Bordeaux, 33600 Pessac, France.

\section{Authors' contributions}

IH performed most experiments in this paper and wrote the initial manuscript draft. LD cloned VvMYB5bR and VvMYB5bL sequences and transformed tobacco. JB, AM, FR and CTM participated in experiments (dual luciferase assays, tobacco transformation, gel shift assays and GRT-PCR, respectively). BG and TG contributed to analysis and interpretation of structural data. VL, FB and LD conceived the study, participated in the preparation and finalization of the manuscript. EG has revised the manuscript critically for intellectual content. All authors read and approved the final manuscript.

\section{Authors' information}

IH present address: Groupe de Recherche en Physiologie végétale (GRPV), Earth and Life Institute (ELI), Université catholique de Louvain (UCL), B-1348 Louvain-la-Neuve, Belgium.

\section{Competing interests}

The authors declare that they have no competing interests.

Received: 30 March 2011 Accepted: 23 August 2011

Published: 23 August 2011

\section{References}

1. Jiang C, Gu X, Peterson T: Identification of conserved gene structures and carboxyterminal motifs in the MYB gene family of Arabidopsis and Oryza sativa L. ssp.indica. Genome Biol 2004, 5(7):R46.

2. Yanhui $C$, Xiaoyuan $Y$, Ku H, Meihua $L$, Jigang $L$, Zhaofeng $G$, Zhiqiang $L$, Yunfei Z, Xiaoxiao W, Xiaoming Q, Yunping S, Li Z, Xiaohui D, Jingchu L, Xing-Wang D, Zhangliang C, Hongya G, Li-Ji Q: The MYB transcription factor superfamily of Arabidopsis: expression analysis and phylogenetic comparison with the rice MYB family. Plant Mol Biol 2006, 60:107-124.

3. Matus JT, Aquea F, Arce-Johnson P: Analysis of the grape MYB R2R3 subfamily reveals expanded wine quality-related clades and conserved gene structure organization across Vitis and Arabidopsis genomes. BMC Plant Biol 2008, 8:83.

4. Dubos C, Stracke R, Grotewold E, Weisshaar B, Martin C, Lepiniec L: MYB transcription factors in Arabidopsis. Trends Plant Sci 2010, 15:573-581.

5. Bomal C, Bedon F, Caron S, Mansfield SD, Levasseur C, Cooke JEK, Blais S, Tremblay L, Morency M-J, Pavy N, Grima-Pettenati J, Séguin A, MacKay J: Involvement of Pinus taeda MYB1 and MYB8 in phenylpropanoid metabolism and secondary cell wall biogenesis: a comparative in planta analysis. J Exp Bot 2008, 59:3925-3939.

6. Mellway RD, Tran LT, Prouse MB, Campbell MM, Constabel CP: The woundpathogen-, and ultraviolet B-responsive MYB134 gene encodes an R2R3 MYB transcription factor that regulates proanthocyanidin synthesis in poplar. Plant Physiol 2009, 150:924-941.

7. Zhou J, Lee C, Zhong R, Ye Z-H: MYB58 and MYB63 are transcriptional activators of the lignin biosynthetic pathway during secondary cell wall formation in Arabidopsis. Plant Cell 2009, 21:248-266.

8. Allan AC, Hellens RP, Laing WA: MYB transcription factors that colour our fruit. Trends Plant Sci 2008, 13:99-102.

9. Nakatsuka T, Haruta KS, Pitaksutheepong C, Abe Y, Kakizaki Y, Yamamoto K, Shimada N, Yamamura S, Nishihara M: Identification and characterization of R2R3-MYB and bHLH transcription factors regulating anthocyanin biosynthesis in gentian flowers. Plant Cell Physiol 2008, 49:1818-1829.

10. Hichri I, Barrieu F, Bogs J, Kappel C, Delrot S, Lauvergeat V: Recent advances on the transcriptional regulation of the flavonoid biosynthetic pathway. J Exp Bot 2011.

11. Spelt C, Quattrocchio F, Mol JNM, Koes R: anthocyanin1 of petunia encodes a basic helix-loop-helix protein that directly activates transcription of structural anthocyanin genes. Plant Cell 2000, 12:1619-1631.

12. Spelt C, Quattrocchio F, Mol J, Koes R: ANTHOCYANIN1 of petunia controls pigment synthesis, vacuolar $\mathrm{pH}$, and seed coat development by genetically distinct mechanisms. Plant Cell 2002, 14:2121-2135.

13. Quattrocchio F, Verweij W, Kroon A, Spelt C, Mol J, Koes R: PH4 of petunia is an R2R3 MYB protein that activates vacuolar acidification through interactions with basic-Helix-Loop-Helix transcription factors of the anthocyanin pathway. Plant Cell 2006, 18:1274-1291

14. Gonzalez A, Zhao M, Leavitt JM, Llyod AM: Regulation of the anthocyanin biosynthetic pathway by the $\pi \mathrm{G} 1 / \mathrm{bHLH} / \mathrm{Myb}$ transcriptional complex in Arabidopsis seedlings. Plant J 2008, 53:814-827.

15. Walker AR, Lee E, Bogs J, McDavid DAJ, Thomas MR, Robinson SP: White grapes arose through the mutation of two similar and adjacent regulatory genes. Plant J 2007, 49:772-785.

16. Cutanda-Perez M-C, Ageorges A, Gomez C, Vialet S, Terrier N, Romieu C, Torregrosa L: Ectopic expression of VImybA1 in grapevine activates a narrow set of genes involved in anthocyanin synthesis and transport. Plant Mol Biol 2009, 69:633-648.

17. Bogs J, Jaffé FW, Takos AM, Walker AR, Robinson SP: The grapevine transcription factor VVMYBPA1 regulates proanthocyanidin synthesis during fruit development. Plant Physiol 2007, 143:1347-1361.

18. Terrier N, Torregrosa L, Ageorges A, Vialet S, Verriès C, Cheynier V, Romieu C: Ectopic expression of VvMybPA2 promotes proanthocyanidin biosynthesis in Vitis vinifera L. and suggests additional targets in the pathway. Plant Physiol 2009, 149:1028-1041. 
19. Czemmel S, Stracke R, Weisshaar B, Cordon N, Harris NN, Walker AR, Robinson SP, Bogs J: The grapevine R2R3-MYB transcription factor VvMYBF1 regulates flavonol synthesis in developing grape berries. Plant Physiol 2009, 151(3):1513-1530.

20. Deluc L, Barrieu F, Marchive C, Lauvergeat V, Decendit A, Richard T, Carde JP, Merillon JM, Hamdi S: Characterization of a grapevine R2R3MYB transcription factor that regulates the phenylpropanoid pathway. Plant Physiol 2006, 140:499-511.

21. Deluc L, Bogs J, Walker AR, Ferrier T, Decendit A, Merillon J-M, Robinson SP, Barrieu F: The transcription factor VvMYB5b contributes to the regulation of anthocyanin and proanthocyanidin biosynthesis in developing grape berries. Plant Physiol 2008, 147:2041-2053.

22. Hichri I, Heppel SC, Pillet J, Léon C, Czemmel S, Delrot S, Lauvergeat V, Bogs J: The basic helix-loop-helix transcription factor MYC1 is involved in the regulation of the flavonoid biosynthesis pathway in grapevine. $\mathrm{Mol}$ Plant 2010, 3:509-523.

23. Matus JT, Cañón P, Bordeu E, Alcalde JA, Arce-Johnson P: Isolation of WDR and bHLH genes related to flavonoid synthesis in grapevine (Vitis vinifera L.). Plant Mol Biol 2010, 72:607-620.

24. Grotewold E, Sainz MB, Tagliani L, Hernandez JM, Bowen B, Chandler VL: Identification of the residues in the Myb domain of maize $\mathrm{C} 1$ that specify the interaction with the bHLH cofactor R. Proc Natl Acad Sci USA 2000, 97:13579-13584.

25. Hernandez JM, Heine GF, Irani NG, Feller A, Kim M-G, Matulnik T, Chandler VL, Grotewold E: Different mechanisms participate in the Rdependent activity of the R2R3 MYB transcription factor C1. J Biol Chem 2004, 279:48205-48213.

26. Pattanaik $\mathrm{S}$, Xie $\mathrm{CH}$, Yuan $\mathrm{L}$ : The interaction domains of the plant Myc-like bHLH transcription factors can regulate the transactivation strength. Planta 2008, 227:707-715

27. Payne CT, Zhang F, Lloyd AM: GL3 encodes a bHLH protein that regulates trichome development in Arabidopsis through interaction with GL1 and TTG1. Genetics 2000, 156:1349-1362.

28. Zhang F, Gonzalez A, Zhao M, Payne T, Llyod A: A network of redundant bHLH proteins functions in all TTG1-dependent pathways of Arabidopsis. Development 2003, 130:4859-4869.

29. Yoshida K, Iwasaka R, Kaneko T, Sato S, Tabata S, Sakuta M: Functional differentiation of Lotus japonicus TT2s, R2R3-MYB transcription factors comprising a multigene family. Plant Cell Physiol 2008, 49:157-169.

30. Ogata K, Morikawa S, Nakamura H, Sekikawa A, Inoue T, Kanai H, Sarai A, Ishii S, Nishimura Y: Solution structure of a specific DNA complex of the Myb DNA-binding domain with cooperative recognition helices. Cell 1994, 79:639-648.

31. Ogata K, Morikawa S, Nakamura H, Hojo H, Yoshimura S, Zhang R, Aimoto S, Ametani Y, Hirata Z, Sarai A, et al: Comparison of the free and DNA-complexed forms of the DNA-binding domain from c-Myb. Nat Struct Biol 1995, 2:309-320.

32. Jin H, Martin C: Multifunctionality and diversity within the plant MYBgene family. Plant Mol Biol 1999, 41:577-585

33. Aravind L, Anantharaman V, Balaji S, Babu MM, lyer LM: The many faces of the helix-turn-helix domain: Transcription regulation and beyond. FEMS Microbiol Rev 2005, 29:231-262.

34. Zimmermann IM, Heim MA, Weisshaar B, Uhrig JF: Comprehensive identification of Arabidopsis thaliana MYB transcription factors interacting with R/B-like BHLH proteins. Plant J 2004, 40:22-34.

35. Solano R, Fuertes A, Sanchez-Pulido L, Valencia A, Paz-Ares J: A single residue substitution causes a switch from the dual DNA binding specificity of plant transcription factor MYB.Ph3 to the animal c-MYB specificity. J Biol chem 1997, 272:2889-2895.

36. Ogata K, Kanei-Ishii C, Sasaki M, Hatanaka H, Nagadoi A, Enari M, Nakamura H, Nishimura Y, Ishii S, Sarai A: The cavity in the hydrophobic core of Myb DNAbinding domain is reserved for DNA recognition and trans-activation. Nat Struct Biol 1996, 3:178-187.

37. Ness SA, Marknell A, Graf T: The v-myb oncogene product binds to and activates the promyelocyte-specific mim-1 gene. Cell 1989, 59:1115-1125.

38. Introna M, Golay J, Frampton J, Nakano T, Ness SA, Graf T: Mutations in vmyb alter the differentiation of myelomonocytic cells transformed by the oncogene. Cell 1990, 63:1289-1297.
39. Kowenz-Leutz E, Herr P, Niss K, Leutz A: The homeobox gene GBX2, a target of the myb oncogene, mediates autocrine growth and monocyte differentiation. Cell 1997, 91:185-195.

40. Tahirov TH, Sato K, Ichikawa-Iwata E, Sasaki M, Inoue-Bungo T, Shiina M, Kimura K, Takata S, Fujikawa A, Morii H, Kumasaka T, Yamamoto M, Ishii S, Ogata K: Mechanism of c-myb-C/EBP beta cooperation from separated sites on a promoter. Cell 2002, 108:57-70.

41. Tanikawa J, Yasukawa T, Enari M, Ogata K, Nishimura Y, Ishii S, Sarai A: Recognition of specific DNA sequences by the c-myb protooncogene product: role of three repeat units in the DNA-binding domain. Proc Natl Acad Sci USA 1993, 90:9320-9324.

42. Belduz AO, Lee EJ, Harman JG: Mutagenesis of the cyclic AMP receptor protein of Escherichia coli: targeting positions 72 and 82 of the cyclic nucleotide binding pocket. Nucleic Acids Res 1993, 21:1827-1835.

43. Tutar $Y$, Harman JG: Effect of salt bridge on transcription activation of CRPdependent lactose operon in Escherichia coli. Arch Biochem Biophys 2006, 453:217-223.

44. Triezenberg SJ: Structure and function of transcriptional activation domains. Curr Opin Genet Dev 1995, 5:190-196.

45. Blau J, Xiao H, McCracken S, O'Hare P, Greenblatt J, Bentley D: Three functional classes of transcriptional activation domain. Mol Cell Biol 1996, 16:2044-2055.

46. Fields S, Song O: A novel genetic system to detect protein-protein interactions. Science 1989, 340:245-246.

47. Ness SA: Myb binding proteins: regulators and cohorts in transformation. Oncogene 1999, 18:3039-3046.

48. Quattrocchio F, Wing JF, van der Woude K, Mol JNM, Koes R: Analysis of bHLH and MYB domain proteins: species specific regulatory differences are caused by divergent evolution of target anthocyanin genes. Plant $J$ $1998,13: 475-488$.

49. Schwinn K, Venail J, Shang Y, Mackay S, Alm V, Butelli E, Oyama R, Bailey P, Davies K, Martin C: A small family of MYB-regulatory genes controls floral pigmentation intensity and patterning in the genus Antirrhinum. Plant Cell 2006, 18:831-851.

50. Elomaa P, Mehto M, Kotilainen M, Helariutta Y, Nevalainen L, Teeri TH: A bHLH transcription factor mediates organ, region and flower type specific signals on dihydroflavonol-4-reductase ( $d f r)$ gene expression in the inflorescence of Gerbera hybrida (Asteraceae). Plant J 1998, 16:93-99.

51. Pattanaik S, Kong Q, Zaitlin D, Werkman JR, Xie CH, Patra B, Yuan L: Isolation and functional characterization of a floral tissue-specific R2R3 MYB regulator from tobacco. Planta 2010, 231:1061-1076.

52. Gabrielsen OS, Sentenac A, Fromageot P: Specific DNA binding by c-Myb: evidence for a double helix-turn-helix-related motif. Science 1991, 253:1140-1143.

53. Murashige T, Skoog F: A revised medium for rapid growth and bioassays with tobacco tissue culture. Physiol Plant 1962, 15:473-477.

54. Takos AM, Jaffé F, Jacob SR, Bogs J, Robinson SP, Walker AR: Light-induced expression of a MYB gene regulates anthocyanin biosynthesis in red apples. Plant Physiol 2006, 142:1216-1232.

55. Kopp J, Guex N, Peitsch MC: SWISS-MODEL: An automated protein homology-modeling server. Nucleic Acids Res 2003, 31:3381-3385.

56. Emsley P, Cowtan K: Coot: model-building tools for molecular graphics. Acta Crystallogr D Biol Crystallogr 2004, 60:2126-2132.

57. Adams PD, Afonine PV, Bunkóczi G, Chen VB, Davis IW, Echols N, Headd Jנ, Hung LW, Kapral GJ, Grosse-Kunstleve RW, McCoy AJ, Moriarty NW, Oeffner R, Read RJ, Richardson DC, Richardson JS, Terwilliger TC, Zwart PH: PHENIX: a comprehensive Python-based system for macromolecular structure solution. Acta Crystallogr D Biol Crystallogr 2010, 66:213-221.

58. Horsch RB, Fry JE, Eichlotz D, Rogers SG, Frakey RT: A simple and general method for transferring genes into plants. Science 1985, 227:1229-1231.

59. Reid KE, Olsson N, Schlosser J, Peng F, Lund ST: An optimized grapevine RNA isolation procedure and statistical determination of reference genes for real-time RT-PCR during berry development. BMC Plant Biol 2006, 6:1-11

60. Vandesompele J, De Preter K, Pattyn F, Poppe B, Van Roy N, De Paepe A, Speleman F: Accurate normalization of real-time quantitative RT-PCR data by geometric averaging of multiple internal control genes. Genome Biol 2002, 3:research0034.1-research0034.11. 
61. Gouet P, Courcelle E, Stuart DI, Metoz F: ESPript: multiple sequence alignments in PostScript. Bioinformatics 1999, 15:305-308.

62. DeLano WL: The PyMOL Molecular Graphics System. 2002 [http://www. pymol.org].

63. Horstmann V, Huether CM, Jost W, Reski R, Decker EL: Quantitative promoter analysis in Physcomitrella patens: a set of plant vectors activating gene expression within three orders of magnitude. BMC Biotechnol 2004, 4:1-13.

doi:10.1186/1471-2229-11-117

Cite this article as: Hichri et al:: A single amino acid change within the R2 domain of the VvMYB5b transcription factor modulates affinity for protein partners and target promoters selectivity. BMC Plant Biology 2011 11:117

Submit your next manuscript to BioMed Central and take full advantage of:

- Convenient online submission

- Thorough peer review

- No space constraints or color figure charges

- Immediate publication on acceptance

- Inclusion in PubMed, CAS, Scopus and Google Scholar

- Research which is freely available for redistribution

Submit your manuscript at www.biomedcentral.com/submit 